\title{
OS DESAFIOS DA VALORIZAÇÃO DA MEMÓRIA E HISTÓRIA LOCAL EM CAMBIRA (PR) A PARTIR DO ESTUDO DAS INTERAÇÕES SOCIAIS NOS LIMITES PAROQUIAIS
}

\author{
THE CHALLENGES OF THE VALUATION OF MEMORY AND LOCAL HISTORY IN \\ CAMBIRA (PR) IN RELATION TO THE STUDIES OF SOCIAL INTERECTIONS WITHIN \\ THE PARISH LIMITS
}

Alessandro Arzani ${ }^{1}$

\begin{abstract}
Resumo: A partir do projeto de extensão "História Local: a Educação Patrimonial e o Exercício da Cidadania" lançado em 2008 com o apoio da Secretaria de Estado da Ciência, Tecnologia e Ensino Superior (SETI) foi possível desenvolver junto à comunidade local de Cambira, Bom Sucesso e Marumbi, no Estado do Paraná inúmeras competências aplicadas à história local, ao patrimônio cultural e ambiental. Tomando os levantamentos documentais e os trabalhos desenvolvidos em Cambira constatou-se certo entrelaçamento entre a memória e as experiências vivenciadas em torno das programações da Igreja católica. Por meio de uma série de correlações estabelecidas através de indícios, sinais e sintomas, identificando seu significado à luz de seu próprio contexto, somados ainda aos procedimentos da história oral, apresenta-se neste artigo o produto do exame dos desafios da valorização da memória e da história local a partir do estudo das interações sociais. É um campo útil a educação patrimonial por oferecer elementos que vinculam a geração atual às memórias de tempos passados.
\end{abstract}

Palavras-chave: História local. Paróquia. Interações sociais. Educação patrimonial.

ABSTRACT: Starting from the extension project "História Local: a Educação Patrimonial e o Exercício da Cidadania" launched in 2008 with the support of Ministry of Science, Technology and Higher Education (SETI), it was possible to develop within the local community of Cambira, Bom Sucesso and Marumbi (Paraná), numerous competencies applied to the local history, and to the cultural and environmental heritage. Taking in particular the documentary surveys and the work developed on Cambira it was verified certain interweaving between memory and experiences lived around the schedules of the Catholic Church. Therefore, through a series of correlations established by means of evidence, signs and symptoms, identifying their meaning in the light of its own context, added the procedures of oral history, it is presented in this article the exam of the challenges of the valuation of memory and local history in Cambira from the study of social interactions. It is a field useful to heritage education by offering numerous elements linking the present generation to those of times past memories.

Keywords: Local History. Parish. Social interactions. Patrimonial education.

1 Doutorando em História pela Universidade Federal do Rio Gande do Sul (UFRGS/Capes). Mestre e graduado em História pela Universidade Estadual de Maringá (UEM). Bacharel em Teologia pela Unviersidade Presbiteriana Mackenzie. 


\section{Introdução}

O estudo da história local se diferencia diante de "grandes temas universais" relacionados a objetos já consagrados pela historiografia mundial. Essa especificidade se manifesta na delimitação de um campo ou região dentro de um nível mais amplo e na busca por aspectos relacionados à vida cotidiana das pessoas. Não se trata de um campo novo dos estudos históricos, mas cabe ressaltar que no mundo globalizado a história local tem a relevância de refletir sobre o lugar em que se vive, como foram produzidas as tradições, os costumes, as características político-sociais, a identidade local e suas relações com as macrorregiões e seu macrocosmo.

Tendo em vista o desafio de formar cidadãos capazes de pensar sobre sua condição local e de interpretar os elementos representativos de sua cultura e região, foi lançado em 2008 com o apoio da Secretaria de Estado da Ciência, Tecnologia e Ensino Superior (SETI) o projeto "História Local: a Educação Patrimonial e o Exercício da Cidadania", coordenado pela Prof. a Dr. ${ }^{a}$ Sandra C. A. Pelegrini. Além de "fortalecer o intercâmbio de conhecimentos entre a Educação Básica Pública e o Ensino Superior" e promover a "popularização das atividades desenvolvidas no âmbito acadêmico", esse projeto tinha por objetivo "instrumentalizar professores do Ensino Fundamental e Médio com materiais e métodos capazes de valorizar a história local, o patrimônio cultural e ambiental, de modo a fomentar o exercício da cidadania entre a população residente nos municípios de Bom Sucesso, Cambira e Marumbi - Paraná". Esses três municípios foram escolhidos para o desenvolvimento do projeto por terem uma população relativamente baixa e não apresentar nenhum destaque histórico-cultural já contemplado, proporcionando assim o desafio da valorização da memória e dos aspectos culturais locais em contrapartida ao esquecimento e aos discursos macroscópicos e universalizastes.

Na primeira etapa do projeto foi necessário conhecer melhor a região e levantar variados tipos de documentos que proporcionassem uma visão geral dos municípios para então partir para os pontos específicos do trabalho. Neste período, foram meses de atividades trabalhosas, com sucessivas viagens entre a sede do CEAPAC-UEM e as respectivas cidades, o que nos rendeu o levantamento muitas fotografias, textos de 
memorialistas, anotações de professores, jornais antigos, testemunho oral de antigos moradores e documentos paroquiais.

Após a análise do corpus documental formado, foi possível perceber a recorrência de elementos da memória que apontavam sempre para cenas do passado em torno da vida paroquial. Fotos da Igreja, narrativas das festas da paróquia, relatos de como a juventude interagia nos festivais e nos momentos após a missa. Esses sinais chamaram a atenção para o desafio de desenvolver estudos sobre as interações sociais nos limites paroquiais, atentando para o valor das práticas de sociabilidade na construção das memórias locais. Tendo em vista a importância desta perspectiva o desdobramento de uma análise da história de grupos, cidades, vilas, ou mesmo "paróquias", propõe-se neste artigo uma reflexão sobre as atividades sociais nos limites paroquiais tendo em vista a necessidade da valorização da memória e o incentivo ao desenvolvimento da história local de pequenas cidades, tomando como campo experimental Cambira, no Estado do Paraná.

\section{Por uma redescoberta da história paroquial}

A missa tem uma importante presença na sociedade brasileira desde a chegada dos portugueses ao continente. A religião acompanhou a expansão para o interior das novas terras. Estudando o espaço de uma pequena população como a de Cambira foi possível encontrar um número significativo de vestígios da memória das interações sociais ou formas de sociabilidades que contornam as atividades religiosas e enfim paroquiais.

O termo 'paróquia' provém do vocábulo grego parokia, substantivo que nomeia a "morada", a "habitação", o "residir como estrangeiro" ou em "condição de exilado". Deriva do verbo paroikew, que significa literalmente "habitar junto"; e ainda pode ser empregado como "residir", ou "habitar em". Com o tempo, a palavra "paroquia" passou a ser usada para se referir à assembleia ou à igreja na Era Cristã. A definição padrão para "paróquia" no Código de Direito Canônico da Igreja Católica estabelece que "Paróquia é uma determinada comunidade de fiéis, constituída estavelmente na 
Igreja particular, e seu cuidado pastoral é confiado ao pároco como a seu pastor próprio, sob a autoridade do Bispo diocesano" (Cân. $515 \S 1^{\circ}$ ). O Código determina também que "toda diocese ou outra Igreja particular seja dividida em partes distintas ou paróquias" (Cân. $374 \S 1^{\circ}$ ). As paróquias são circunscrições eclesiásticas territoriais que compreendem todos os fiéis de um determinado território. Também costumam ser chamada de "freguesia", evidentemente com uma conotação laica. Segundo James A. Corriden (1999, p. 6) a comunidade paroquial é a igreja local cujos membros têm variados graus de participação e mútua interação, de comprometimento e ativo engajamento. Mas a paróquia também estabelece limites territoriais e em alguns países ou regiões acabam sendo sinônimo de 'município'. Essa relação é bantante compreensível, considerando que a organização da diocese em várias paróquias é uma estratégia administrativa. No entanto, não é uma regra geral os limites municipais serem os mesmos que os das paróquias. Um município pode ter inúmeras paróquias.

Os estudos históricos sobre as "paróquias" remontam ao século XVIII. John Southerden Burn (1867), pesquisador dos registros paroquiais ingleses, sentiu-se incomodado ao perceber que a obra de Mr. Bigland, Observations on Parish Registers (publicada por volta de 1766), era uma das únicas sobre os registros de paróquia até o final do século XVIII. Esse tipo de investigação ascendeu na Inglaterra, pois lá existia o modelo de civil parish, o que tornava a análise dos arquivos eclesiásticos uma atividade promissora para o estudo da sociedade. Nesse modelo o poder 'espiritual' e o 'secular' se inter-relacionam (SMITH, 1857). Atualmente vários estudos demográficos são feitos a partir dos registros paroquiais de batismo, casamentos, mortes e enterros, como a reconstrução da história populacional da Inglaterra desenvolvida por Edward Anthony Wrigley e Roger Schofield (2002). O estudo dos arquivos paroquiais tem possibilitado o entrecruzamento de informações para compreensão dos aspectos religiosos, culturais, políticos e econômicos de determinadas sociedades.

Katherine French, Gary Gibbs e Beat A. Kümin (1997) desenvolvem uma ampla análise da vida paroquial na Inglaterra entre 1400 e 1600, relacionando os mais variados aspectos que possam contar um pouco da história daquele período. Ademais, 
os registros paroquiais, como observa Maria Luiza Marćlio (2004, pp. 13-20), tornaram-se importantes para o controle social a partir do Concílio de Trento, pois muitas regiões europeias estavam se tornando protestantes e era preciso distinguir o perfil demográfico das sociedades. Por fornecerem dados sobre a vida das pessoas da sociedade do nascimento à morte, os registros podem ser explorados para diversas análises históricas.

Por meio de uma série de correlações estabelecidas através de indícios, sinais e sintomas, identificando seu significado à luz de seu próprio contexto (LEVI, 1992), devem-se analisar os vestígios das interações sociais na comunidade católica de Cambira-PR. Embora trate-se de um município com poucos anos de existência, não é uma tarefa fácil encontrar alguns dos seus fundadores. Uma boa parte já faleceu e outros se mudaram com suas famílias para outras regiões. Ainda assim, é possível conseguir entrevistas, desenvolvidas por meio da metodologia da história oral (PRINS, 1992). Certamente uma investigação micro-histórica oferece subsídios para que sejam relacionadas informações coletadas às memórias de alguns membros da população residente e perceber seus elementos dinamizadores.

\section{As atividades na paróquia e a memória local}

Em 30 de abril de 1959, o Bispo de Londrina Dom Geraldo Fernandes CMF ${ }^{2}$ institui a Paróquia de Cambira. Uma paróquia, no entanto, não vem à existência apenas mediante uma assinatura. Há um processo de formação da comunidade religiosa que antecede esse ato episcopal. Para se compreender a organização de uma paróquia é preciso entender, antes, o processo de formação de comunidade.

A área que hoje forma o município de Cambira, na Microrregião 8 do Norte Central do Estado do Paraná fazia parte do Município de Apucarana-PR (KOHLHEPP, 2014). Apucarana passou por um período de desenvolvimento na década de 1940, principalmente com a chegada da ferrovia. O Norte do Paraná, em grande medida

\footnotetext{
${ }^{2}$ CMF = Cordis Mariae Filius. É esta a sigla oficial que cada Missionário Filho do Coração de Maria (Claretiano).
} 
devido a um excelente trabalho de Marketing para a comercialização de terras, atraía pessoas de diversas regiões. O café tornou-se uma das principais culturas (KOHLHEPP, 2014). Cambira é o nome dado a um cipó com flor lilás que era muito comum na região. O cipó deu nome a Estrada da Cambira, que hoje é a Avenida Belo Horizonte da cidade, passando ao lado da Igreja Matriz e seguindo como "Rodovia do Milho" para o Bairro Bela Vista.

Encontrar fontes e informações sobre a formação do vilarejo que deu origem a Cambira exigiu muita conversa com seus moradores e questionários sobre informações, registros ou fotos. Pelo menos dois cidadãos já haviam tentado compilar informações sobre as origens de Cambira em livretos: o Sr. Narciso Capeloto (1998) e o Sr. Nivalci Claudiano (1997). Ambos os textos, com inúmeras semelhanças, são anotações de caráter memorialista, valorizando e supervalorizando nomes de famílias e personalidades de destaque nos anos de formação do vilarejo de Cambira. Mas o trabalho de ambos tem o mérito de compilar informações importantes sobre a memória local.

Maurice Halbwachs (1968) já apontava que é preciso buscar referências que estruturam a memória e a introduzem na memória da coletividade. Dentre esses pontos estão os monumentos, o patrimônio arquitetônico, as paisagens, as datas e personagens históricos de cuja importância somos incessantemente relembrados, bem como as tradições e costumes, certas regras de interação, o folclore, a culinária, a música, etc. E se tratando de pequenas cidades ou vilarejos, destaca-se o desafio de opor-se ao esquecimento que inibe a capacidade do povo local de compreender o espaço, as relações sociais e a sua própria condição de existência. Às vezes é preciso encontrar os vestígios da memória no silêncio.

Como destacava Le Goff (1990, p. 535), o "interesse da memória coletiva e da história já não se cristaliza exclusivamente sobre os grandes homens, os acontecimentos, a história que avança depressa, a história política, diplomática, militar". Há várias décadas, a história passou a abranger novos objetos e a contemplar novos problemas. Nestes novos campos, o registro paroquial que conserva para a memória vários aspectos da vida comunitária. Neles são assinalados, os nascimentos, 
os matrimônios, as mortes e por meio desses registros também são destacadas as atividades que mobilizavam a comunidade.

Segundo Pierre Nora (apud LE GOFF, 1990. pp. 473-474), a "memória coletiva" é "o que fica do passado no vivido dos grupos, ou o que os grupos fazem do passado". A memória deve ser compreendida como "um elemento essencial do que se costuma chamar identidade, individual ou coletiva, cuja busca é uma das atividades fundamentais dos indivíduos e das sociedades de hoje, na febre e na angústia" (1990, p. 477). Pode-se dizer que uma das camadas do "vivido" se estabelece nas interrelações protagonizadas na comunidade religiosa, ou paroquial, e tende muitas vezes a ser ignorada e deixada no silêncio.

Cambira conta com aproximadamente 7.237 habitantes (IBGE, 2010), a maior parte de sua população é católica e como tantas cidades tem em seu centro urbano o prédio da Matriz. A Igreja Matriz pode ser considerada um monumentum das interações locais, pois como destaca Le Goff, "o monumentum é um sinal do passado, [...] é tudo aquilo que pode evocar o passado, perpetuar a recordação".

Desde a década de 1930, a região passou a receber migrantes, que vinham se estabelecer em propriedades rurais na região. Capeloto (1997) considera que a maior onda de migrantes para a região ocorreu entre 1940 e 1950, nessa época as lavouras de café demandavam muita mão-de-obra. A comunidade católica de Cambira, assim como em outros municípios, formou-se devido ao estabelecimento dos novos habitantes na região.

Em 1947, ao lado de onde passa a via férrea, foi formada a Vila Formosa, um loteamento empreendido pelo Sr. Marco José Calsavara, que não havia tido boa sorte depois de se mudar do Estado de São Paulo para o Paraná. No ano de 1954, Júlio Sapatini, Geraldo Marcato e Cecílio Nakad adquiriram de João Davanel desmembraram uma área em lotes urbanos (CAPELOTO, 1997). Gradativamente foi ganhando tamanho um núcleo habitacional significativo no local, por isso em 1953, tornou-se distrito a então chamada Vila São José de Cambira.

Segundo o Sr. Antenor Calsavara, desde 1942 já havia um Cruzeiro cravado no chão pelos primeiros moradores. Depois, no terreno concedido foi construída uma humilde barraca coberta com folhas de palmeira, onde eram celebradas as missas. 
Em 1947 foi construída a primeira Capela, sendo o padroeiro São José. O Sr. Antenor também aponta que a primeira missa na nova capela foi rezada em 19 de março de 1948, pelo Padre Francisco Korner, Vigário da Paróquia de Apucarana-PR.

À medida que crescia o círculo social em desenvolvimento na região da Vila de Cambira, transformava-se também aquilo que pode ser chamado o símbolo da comunidade católica local. Primeiro aparece o Cruzeiro, o símbolo do cristianismo. Depois é erigida uma barraca para a congregação de alguns fiéis. Essa já esboça a ideia de coletividade, pois é o lugar onde pessoas se reúnem para juntas celebrarem religiosamente. Tão logo, os membros se mobilizam para construir uma pequena capela de madeira. Mas esta foi mal projetada, não comportando o número de fiéis participantes da congregação e outra precisou ser elevada.

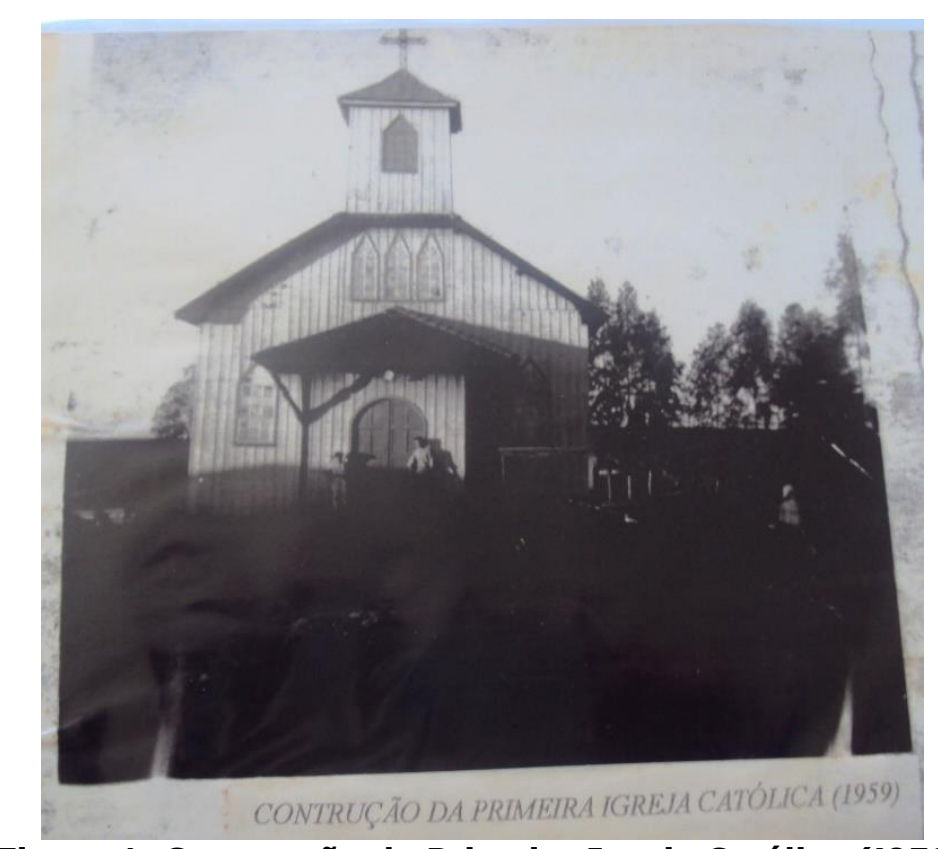

Figura 1: Construção da Primeira Igreja Católica (!959) 


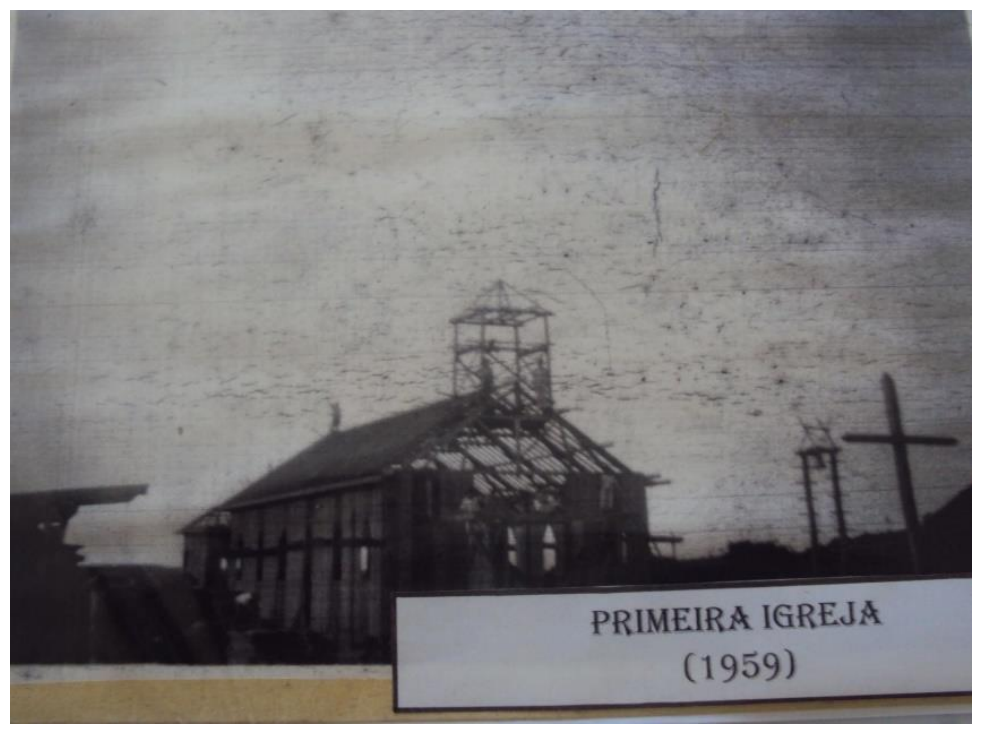

Figura 2: Primeira Igreja

As fig. 1 e 2 foram recolhidas na Biblioteca municipal de Cambira e foram feitas por autores desconhecidos. As legendas são confusas, pois entram em conflito com as informações apresentadas. Provavelmente a Fig. 1 é anterior a 1959. Tempo suficiente para que crescesse vegetação atrás da Igreja como aparece na Fig. 2. Segundo Capeloto (1998), quando o templo em madeira da primeira igreja de Cambira se tornou inadequado devido a suas limitadas dimensões, foi então desmontado e transferido para uma comunidade na zona rural.

Os moradores destes espaços acabavam por estabelecer formas de sociabilidade, religiosidade e cultura, vivenciadas pela comunidade nas práticas religiosas. Dentro de uma comunidade católica são várias as atividades que podem expressar os laços socioparoquiais. Além da liturgia comum às celebrações, cada paróquia tem a oportunidade de desenvolver algumas características próprias. Esses aspectos se manifestam quando grupos de fiéis se organizam na execução de uma programação social que represente diretamente um ideal desenvolvido em função da expressão da fé professada.

Entre as formas possíveis que podem aparecer estão as atividades filantrópicas, as festas para arrecadar fundos para algum fim caridoso ou alguma reza específica. Nesse período que antecede a instituição da paróquia de Cambira-PR, as principais ações responsáveis pela integração da comunidade estão relacionadas à construção 
da Capela e ao exercício de atividades religiosas. Quando essa comunidade já se encontrava(?) suficientemente desenvolvida, passou então a ser uma Paróquia.

Em 1959, o Bispo Dom Geraldo Fernandes nomeou o Pe. Hermínio di Gioia como Pároco da nova Paróquia. O território definido para a paróquia de Cambira foi "separado, dividido e desmembrado" da paróquia de Apucarana, segundo as seguintes divisas, como consta no Decreto episcopal:

Começa na cabeceira do córrego Acanga, desce por ele até a fóz com o Rib.do Marumbí, desce por este até a foz com o Rib.Itacolomi, desce por este até o Rio Bom, sobe até a foz V2do Rib.Cambira, sobe por este até o Corr.Grumichama, atravessa a estrada Apucarana-Jandaia, desce a cabeceira do Corr.Ubatuba. Desce este até a foz com o Rib.dos Dourados, sobe este até a foz do Corrego Ivai, sobe este até a cabeceira, atravessando a Estrada Apucarana-Jandaia, procura a cabeceira do Corr.Acanga, ponto de partida.

O termo de abertura do Livro Tombo apresenta a seguinte expressão: "para que nele sejam relatados os principais acontecimentos da vida paroquial de Cambira". Essa expressão padrão sintetiza a principal finalidade do Livro Tombo. Ele é um espaço da memória, será uma fonte para a história da paróquia, mas não é nem um pouco pleno. É fruto da perspectiva de quem sobre suas páginas registrou o que concebeu como "principais acontecimentos".

A solenidade de posse do primeiro Vigário da nova Paróquia é descrita nas primeiras páginas do Livro Tombo. O Pe. Hermínio di Gioia escreve que o evento "deixou na alma de todos os presentes e" - no seu coração de Sacerdote - "uma grande emoção e no mesmo tempo um grande estímulo para trabalhar animadamente para o bem espiritual de todas as almas" a ele confiadas (LIVRO TOMBO, p. 3).

Na mesma ocasião foi confirmada a primeira diretoria da Paróquia para cooperar na administração. Também foram escolhidos os cargos dos presidentes das Irmandades. Organizada a estrutura administrativa e os grupos religiosos, as próximas atividades desenvolvidas na comunidade podem ser analisadas como uma opção de interação social entre os moradores do distrito. 
Ao buscar refletir sobre as questões que envolvem as atividades paroquiais e a memória dos primeiros passos dessa instituição é possível identificar uma das mais importantes opções de interação social em Cambira. Por morarem próximas umas das outras, as pessoas desenvolviam meios de se socializar e de interagir. Um pequeno núcleo urbano ascende, mas a maioria da população concentrava-se na zona rural.

Conforme considerou Fichter (1978, p. 4), "em essência, então, um entendimento do papel do Catolicismo na sociedade moderna requer um estudo não só de seus valores e significados, mas especialmente dos "veículos" empregados para ativá-lo e dos agentes que acreditam nesses valores e empregam esses veículos". Usando seus próprios termos, esses 'veículos' são analisados como responsáveis pelos desenvolvimentos das atividades interacionais para mobilização da comunidade.

Ainda que a Igreja Católica, por algumas vezes se meta em questões seculares, seu primeiro objetivo como instituição é a salvação dos seres humanos. A paróquia, por sua vez, "é uma instituição humana, desenvolvida para propósitos práticos da administração e mantida como uma área operativa no interior da estrutura social e hierárquica da Igreja" (FICHTER, 1978, p. 12). Tendo em vista a essa perspectiva sociológica sobre essa instituição é possível vislumbrar as relações humanas que aí existem entre o clérigo e os leigos e entre pessoas e grupos em meio aos próprios leigos.

Para se compreender a integração socioparoquial desenvolvida na comunidade é preciso considerar alguns elementos fundamentais. Primeiramente deve-se destacar que a integração implica não só ordem e estrutura, senão também ação e função. Nesse sentido, a integração sociocultural não significa uma estrita homogeneidade. O termo integração, segundo Fichter (1974, p. 416), "significa com frequência um processo social como o de assimilação, amalgama, socialização ou aclimatação cultural".

As pessoas que iam se achegando a Cambira durante sua formação, principalmente na Vila onde se desenvolveria a área urbana, sofreram um processo de integração sociocultural ao adotar gradualmente as pautas de comportamento do novo ambiente, e desenvolvem relações sociais com pessoas que antes Ihes eram 
estranhas. Também dentro da Paróquia existe o exercício de integração através das atividades. A integração de um grupo quer dizer que os membros deste desempenham seus papéis recíprocos em interdependência mútua com o fim de obter os objetivos dos mesmos.

De modo geral entende-se por grupo integrado aquele que logra seus fins com o menor conflito possível. Trata-se de um grupo não apenas bem estruturado, como também cujas relações sociais de seus membros procedem em forma produtiva e prática e acentuando os processos sociais de cooperação, acomodação e assimilação. A essa pesquisa, no entanto, não coube em nenhum momento quantificar o nível de integração socioparoquial, mas analisar o tipo de atividade desenvolvida que possa ter contribuído para mobilização da comunidade. Para isso, três fatores essenciais de integração sociocultural apontados por Fichter (1974) devem ser considerados: consenso de valores; participação nas funções comuns, bem como o grau de voluntariedade; e a multíplice participação das pessoas nos diferentes grupos.

A mobilização da comunidade da Paróquia pode ser analisada através dos apontamentos relativamente cronológicos Livro Tombo e cruzados com o relato oral de alguns moradores. Conforme destacou Sônia M. de Freitas ao prefaciar a obra de Thompson

[...] a história oral pode dar grande contribuição para o resgate da memória [...], mostrando-se um método bastante promissor para a realização de pesquisa em diferentes áreas. [...] $\mathrm{A}$ memória de um pode ser a memória de muitos, possibilitando a evidência dos fatos coletivos (1993, p. 17).

O mês de maio de 1959 foi o mês mariano na Paróquia. No encerramento do mês, as Irmandades de todas as Capelas se juntaram para assistir a Coroação de Nossa Senhora e para a consagração de toda a Paróquia ao Sagrado Coração de Maria.

Junho era o mês da Consagração ao Sagrado Coração de Jesus. Na primeira sexta-feira foi iniciada uma novena em louvor ao Sagrado Coração. O Padre escreveu que durante esse mês, somando todas as noites, 95 famílias foram visitadas e consagradas ao Santíssimo Coração de Jesus. A visita às famílias contribui para a aproximação entre o novo pároco e os fiéis. 
Em agosto foi organizada a primeira festa na Matriz, em louvor a Nossa Senhora Assunta ao Céu. O pregador da Missa Vespertina foi o Pe. Agostinho Cola. Na ocasião da festa foi organizado um concurso de "Rainha do Café". A renda da festa foi usada para pagar as dívidas que foram feitas para instalação da Paróquia.

Sem nenhum comentário sobre o mês de setembro o Padre escreve que o mês de outubro foi consagrado à Reza Solene do Santo Rosário. A participação das crianças chamou a atenção do Pe. Hermínio, que as comparou aos "pastorinhos" de Fátima, por rezarem o Terço "aos pés de Nossa Senhora" (LIVRO TOMBO, p. 4).

Em Dezembro a Comissão da Matriz determina o início da construção de um salão Paroquial multiuso. Poderia ser usado para reunião das Irmandades; para iniciar a escola Paroquial; ou mesmo para a diversão dos fiéis, dando início a um cinema paroquial, teatro, etc. Em 31 de janeiro de 1960 foi realizada uma festa para arrecadar fundos e desenvolver a nova construção. Anota-se que "a festa deu uma renda boa" (LIVRO TOMBO, p. 4). A comunidade pôs em curso seu projeto de organizar uma Escola Paroquial. A inauguração foi marcada para o dia 19 de março, data na qual se celebrava o dia de São José, Padroeiro da Matriz. Para esta ocasião foi marcada uma festa.

No referido dia compareceu o Revmo. Bispo Diocesano Dom Geraldo Fernandes. A vinda de uma autoridade tornava a celebração especial para os moradores. O prédio de 26 metros de comprimento, por 10 de largura, com 5 de altura contribuiria para as variadas atividades sociais. O edifício reserva um espaço para uma máquina de cinema e um palco. O prefeito de Apucarana Marino Pereira, o Pe. Armando Círio do Superior Provincial dos Josefinos e diretorias das Capelas da Paróquia também estiveram presentes para a inauguração. Aproveitando a ocasião o Bispo ministrou Crisma na Matriz. Na parte da tarde o palco foi inaugurado com apresentação de peças teatrais e a máquina de cinema, com um curta-metragem.

O Padre sempre atribui expressões positivas à comunidade. Nesse caso, comenta que a cerimônia foi bem sucedida, "deixando no povo um grande entusiasmo e uma geral satisfação" (LIVRO TOMBO, p. 5). Tais descrições aparecem sempre como aprovação das obras desenvolvidas na Paróquia, como forma de confirmar sua atuação. 
A assim denominada Escola Paroquial "São José do Cambira" teve seu primeiro dia de aula em 21 de março de 1960. A primeira turma era composta de 42 alunos, dos quais 32 frequentavam o $1^{\circ}$. ano e 10 frequentavam o $2^{\circ}$. ano primário, todos das $12 \mathrm{~h}$ às $18 \mathrm{~h} 30$. A professora é descrita como uma pessoa muito envolvida com os trabalhos da paróquia e responsável pela catequização das crianças.

A primeira Semana Santa celebrada em Cambira também movimentou o local. Na Quinta-feira Santa foi celebrada Missa da Santa Ceia. A adoração diante do Santo Sepulcro foi um momento contínuo desde as $19 \mathrm{~h}$ da Quinta-feira até às $15 \mathrm{~h}$ da Sextafeira Santa. Para auxiliar no recebimento de Confissões foi convidado o Pe. Severino Ceratti, diretor do Colégio "São José" de Apucarana-PR. Anota-se que a procissão contou com "um número extraordinário de povo" (LIVRO TOMBO, p. 6). O panorama do pátio da matriz é descrito como uma "imensidão de fiéis". O número de pessoas que compareceram não pode ser estimado, mas por ser a primeira celebração pascal qualquer número ali reunido seria "imenso". Pela primeira vez ocorre no local a bênção do Círio Pascal e da Água Batismal.

É possível notar que a paróquia se desenvolvia e se estruturava. Em oito de maio do mesmo ano foi inaugurada uma Capela em um novo bairro. No mesmo dia foram estabelecidas as Irmandades dos Congregados Marianos, Pia União das Filhas de Maria, Senhoras do Apostolado da Oração e Cruzada Eucarística Infantil. Sobre o povo, anota-se, como em outras ocasiões, que "ficou muito satisfeito [pela] nova Capela, recebendo assim uma grande oportunidade de poder satisfazer com mais facilidade as próprias obrigações religiosas e recepção mais freqüente dos santos sacramentos" (LIVRO TOMBO, p. 7).

O mês de maio foi organizado na Matriz e nas Capelas da Paróquia. O pároco escreve que "para suscitar um pouco de animação e emulação entre as Capelas, foi organizado um Concurso Mariano" (LIVRO TOMBO, p. 7). Em cada Capela ou na Matriz foram escolhidos representantes que receberiam uma imagem de Nossa Senhora que devia percorrer todas as casas do próprio bairro. O grupo que alcançasse o maior número de visitas domiciliares, de reza do Rosário, de frequência do povo (em número de pessoas por noite) e de arrecadação (em dinheiro ou em grãos) seria proclamado no encerramento oficial a realizar-se na Matriz vencedor do Concurso Mariano 1960. 
Cambira ficou agitada durante o evento. No encerramento todas as comunidades das Capelas se dirigiram à Matriz. Anota-se que "nunca viu tanto povo no Cambira e tantas conduções" (LIVRO TOMBO, p. 7). Havia muita gente na cidade. No período da tarde foi realizado um desfile pelas ruas com as imagens das Santas. Num palco enfeitado defronte à Matriz foi dado o resultado: a vencedora do Concurso Mariano foi a Capela de Santo Antônio Itacolomi. Após a proclamação houve a representação de quadros viventes da vida de Nossa Senhora e outros.

Sobre os concursos, festas, reuniões das Irmandades, apresentações teatrais e outras ações o Sr. José Jordão Beleze, sua esposa a Sra. Elena Nakad Beleze e o Sr. Antônio Roberto Toledo Pires afirmam que esse período da história da Paróquia foi bastante animado, com muitas atividades que mobilizavam a comunidade. Aliás, não existiam outras atrações para o povo de Cambira nessa época, exceto algum torneio de futebol que atraía um público considerável. A ida para as cidades vizinhas não era simples, pois normalmente exigia que se tomasse transporte público.

A Sra. Elena comenta que o Pe. Ermínio "era a muito bacana com os jovens [...]. $E[\ldots]$ fizemos teatro na época dele. Ele tinha pilhas de livros, assim, de teatro. [...] Ele convidou um grupo, assim, que tinha interesse, né, e formou um grupo de teatro". As peças eram apresentadas no salão paróquia. Em uma ocasião a Sra. Elena declamou um poema para a abertura de uma peça. "Eu declamei um poema de Castro Alves que eu estava decorando e o padre quis para a abertura do teatro. Eu me lembro de que me emprestaram uma manta $[. .$.$] que veio da Espanha, [. .$.$] tipo um$ chalé grandão", diz ela. O grupo sempre ensaiava com o padre. Ela ainda acrescenta: "naquela época a gente era [...] criança e dava ataque de riso e a gente não conseguia fazer. Mas ele tinha uma paciência e esperava, esperava... Aí a gente fazia certinho". Com entusiasmo ela afirma:

o Pe. Hermínio era muito animado. Tudo que ele fazia, a gente tava no meio. [...] E minha família não era assim muito de igreja, sabe? [...] Mas eu desde pequenininha gostava. Desde a 'cruzadinha'... a gente participava de canto de tudo, Nossa Senhora! Eu vivia lá. Era aquela igreja antiga, de madeira, com o altar tudo cheio de degrauzinho [...]. Depois fui Filha de Maria, 
e comecei a namorar ele [seu esposo José Beleze] e ele também era congregado mariano, né?

Com certa descontração a Sra. Elena também conta que "quando chovia em Cambira era uma 'festa'. Ficava aquele monte de carro atolado na lama". Contava-se com o trem, mas os atrasos deixavam muitas pessoas irritadas. A Sra. Luiza Capelotto relata que as festas e missas da igreja também eram ocasiões para rever os amigos, conversar. A Sra. Elena diz: "eu me lembro muito das festas da igreja, né. Mais era muita gente!". E o Sr. Antônio Roberto confirma: "Era muita gente!". Ambos ao mesmo tempo: "e tinha aquelas barraquinhas em volta". "Então as festas eram assim, muita barraquinha lotada, a outra barraca de brinquedo, aqueles aviõezinhos pra crianças...", diz a Sra. Elena. "coelho, porquinho [de brinquedo]...", acrescenta o Sr. Antônio. "Todo pessoal da Congregação mariana [...] todos trabalhavam... não é como hoje [...]". "Se empenhavam", comenta o Sr. Antônio. O Sr. José Beleze acrescenta que também tinha o futebol. E a Sra. Elena comenta entusiasmada: "até eu gosta? de ir pro campo!". Ela ainda comenta que o máximo que se ia além de Cambira era até Jandaia ou Apucarana, e que "se perdesse o último ônibus, meu Deus!".

Na ocasião da substituição do pároco, com a presença do Bispo Dom Geraldo Fernandes, foi lançada a pedra fundamental da nova Igreja e 296 crianças foram crismadas (LIVRO TOMBO, p. 9). Logo é dado início aos trabalhos da nova Matriz e foi organizada pela Congregação Mariana e da Pia União das Filhas de Maria uma visita domiciliar da imagem de Nossa Senhora a cada família, tanto da Matriz quanto das Capelas. Anota-se que "os fiéis tomam parte a esta devoção com grande fé e confiando em Nossa Senhora" (LIVRO TOMBO, p. 11).

As atividades dos demais meses são apontamentos rápidos. Em junho são realizadas festas nas Capelas dos Bairros Sete de Maio e Santo Antônio. Em julho começa a colheita do café e a campanha em benefício da construção da Matriz. Por volta do mês de agosto as paredes da Matriz já começam a ganhar altura. 


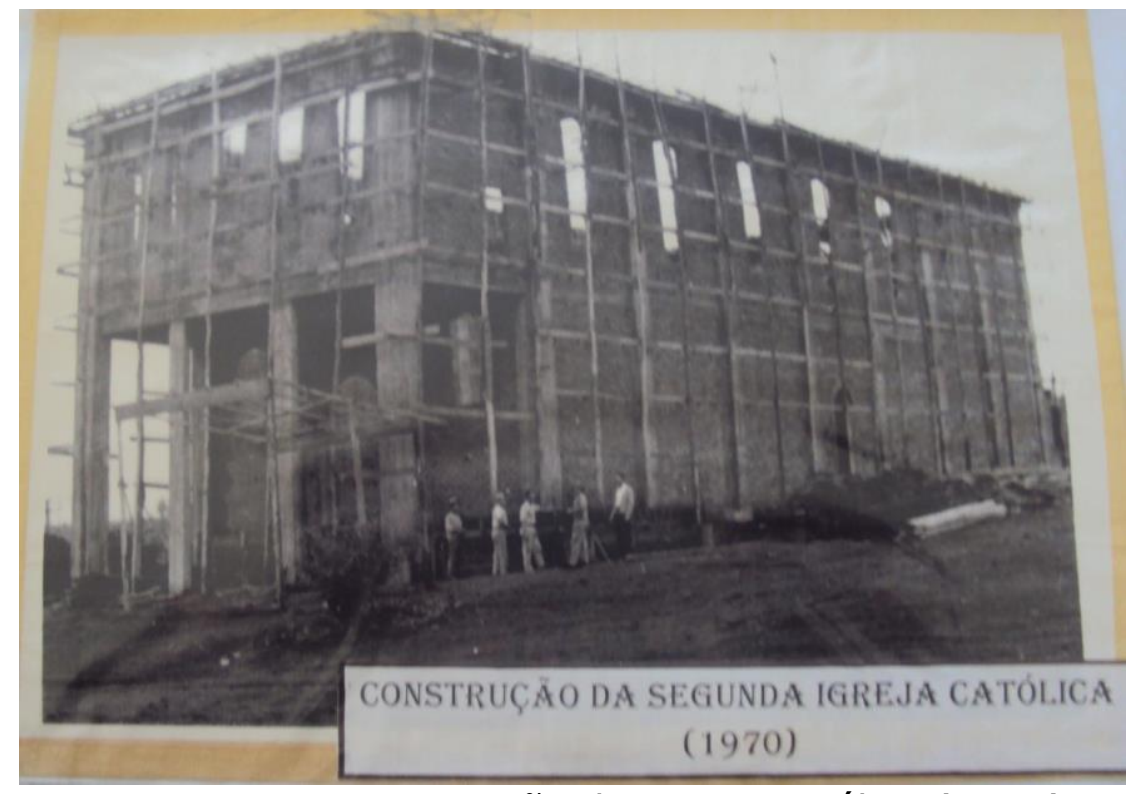

Figura 3: Cosntrução da Igreja Católica (1970)

Também em Itacolomi a nova Igreja já estava com sua construção adiantada. No dia 15 de agosto é realizada a festa de Nossa Senhora da Assunção, padroeira da Capela. A comunidade organizou uma rifa de um Jeep para angariar fundos para a construção da Matriz. Setembro é marcado por festas nas Capelas em louvor a Nossa Senhora Aparecida. Em outubro, o terço é rezado nas Capelas e nas Casas. O motivo principal dessa vez é pedir a Nossa Senhora do Santo Rosário a proteção e o bom êxito no Santo Concílio Ecumênico Vaticano II. No mês de novembro é feita a primeira cinta de concreto da nova Matriz e as paredes se elevam. A festa da Imaculada Conceição é realizada no dia 08 de dezembro. Na véspera do Natal, um vento forte e a chuva derrubam uma parede da nova construção. Nesse período de construção da nova Matriz, o Salão Paroquial serviu de igreja provisória.

O ano de 1963 começou com a retomada da construção da Matriz. O Padre anota que mesmo após os estragos causados pelo vendaval, "o povo, depois do primeiro choque, não desanima e continua a construir generosamente" (LIVRO TOMBO, p. 13). 


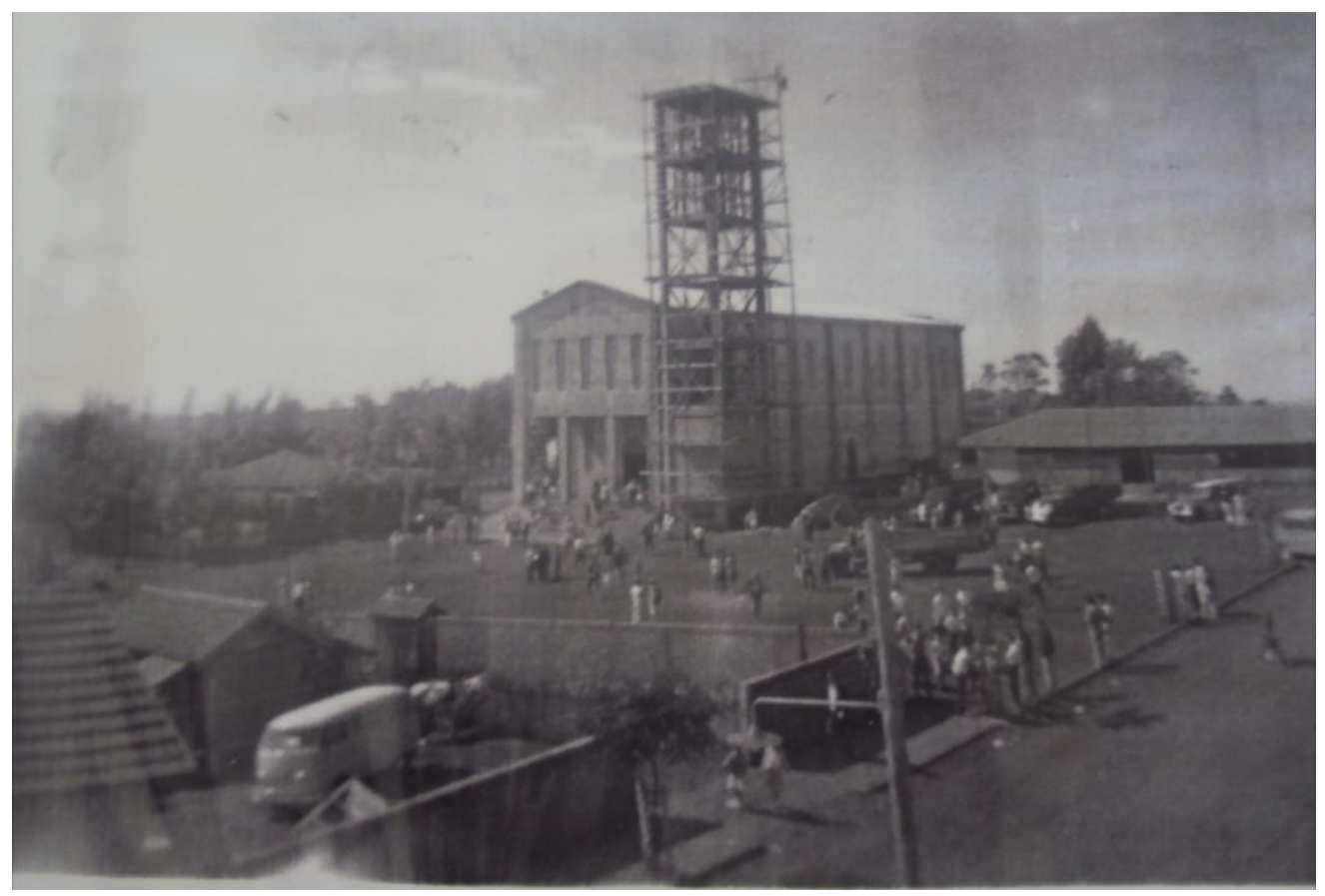

Figura 4

Em Itacolomi, a Igreja que estava em construção já se encontrava coberta e o povo celebrava, no início do ano, a festa de São Sebastião. Em 17 de março, o Bispo visita novamente a Paróquia. Ele também comparece na Matriz em Cambira e na Capela de Itacolomi, onde concede a crisma.

Após a programação pascal do mês de abril, houve reza do terço nas famílias, atividade que dinamizou o mês de maio. Nesse mês a comunidade se organizou em campanha para arrecadar cereais em benefício dos seminaristas com poucos recursos financeiros e também para ajudar nas obras da Paróquia. Anota-se que "todos concorrem e dão de boa-vontade" (LIVRO TOMBO, p. 13).

As anotações sobre os meses de julho e agosto são marcadas por calamidades. Segundo os registros "as lavouras da Paróquia são castigadas por uma prolongada seca, por geadas que acabam com $60 \%$ dos cafezais, o fogo destrói pastarias, casas, tulhas e matas; o povo pede a proteção a N. Sra. Aparecida" (LIVRO TOMBO, p. 13). Percebemos que entre a década de 60 de 70 houve vários problemas naturais que dificultaram a agricultura na região, algo que é analisado melhor por Gerd Kohlhepp (2014). 
Durante o mês de setembro a Paróquia contou com a participação do Missionário Caretiano Pe. Asterio Pascoal. As atividades desse mês movimentaram a comunidade. Por todas as Capelas havia confissões, comunhões, visitas a enfermos e algo que parece ser bastante significativo quanto à integração social: Foram feitas várias regularizações de uniões "ilegítimas" (do ponto de vista católico) e outros que estavam afastados da participação das atividades religiosas foram conduzidos novamente aos sacramentos da Igreja. Conta-se que "foram feitas nove mil comunhões, legitimados quarenta e seis casamentos, feitas 55 práticas, 24 conferências" (LIVRO TOMBO, p. 14-15) e 22 doentes foram visitados. Essa iniciativa procurou aproximar as pessoas mais afastadas das celebrações da Igreja.

No mês de outubro, como nos anos anteriores, rezou-se o rosário. A construção da nova Matriz continuava. O madeiramento já estava cortado e pronto para ser utilizado na solidificação do prédio. Em novembro foi preparado o piso da Igreja e Depois de dezenove meses do lançamento da pedra fundamental da Matriz ela já se encontrava coberta. Desse modo, conforme aponta o Livro de Tombo, as festividades de Natal já puderam ser realizadas na nova Matriz (LIVRO TOMBO, p. 15).

Janeiro de 1964 contou com inúmeras festividades a São Sebastião. Em março ocorrem as celebrações ao Padroeiro São José, para arrecadar fundos para a construção. Na Semana Santa a Paróquia contou novamente com a presença do Pe. Asterio Pascoal (CMF). Em maio todas as irmandades se movimentam para rezar o terço com as famílias. Nesse momento, acontece o "Golpe civil-militar de 1964". O Padre expõe sua visão política ao anotar que diante desses acontecimentos "volta a calma em todo o País" (LIVRO TOMBO, p. 17). Além disso, ele se mostra favorável à intervenção dos militares e pouco antes conclamava o povo para interceder pelo Brasil, para que ficasse livre da "comunização" (LIVRO TOMBO, p. 16).

Em 27 de Dezembro, é assinada pelo Papa a Bula de Criação da Diocese de Apucarana. A nova Diocese passa a ter o primeiro Bispo, na pessoa do Revmo. Dom Romeu Alberti. A celebração de elevação da Diocese e posse do Bispo aconteceu em 28 de Março de 1965. Anota-se que vinte mil pessoas compareceram à cerimônia. A Paróquia de Cambira passa a fazer parte dessa Diocese. 
A professora Selena Della Pietra, que chegou com sua família em Cambira por volta do ano de 1961, relata que não havia muita gente na cidadezinha. Grande parte da população estava concentrada na zona rural. Com a fala marcada pela emoção da recordação, ela diz que:

As festas eram festinhas de igreja né. Quando tinham que comemorar o padroeiro... quando fazia algum almoço. Era pouca gente que tinha. O pessoal morava muito no sítio. No sítio mesmo que a gente morava ali tinha uma família. Eu dava dois períodos de aula, cedo e à tarde. E também viajava a cavalo lá nos alemães. No começo eu ia a cavalo. Naquele tempo tinha bastante alemães e poloneses.

Não há muitas fontes de informação sobre a atividade religiosa na zona rural, mas a professora Selena contribui com informações de como eram as atividades entre os jovens no campo em meados da década de 60 .

No sítio era muita gente, sabe?! O povo lá gostava de andar à noite. Passar em casa, contar história, brincar. A gente não tinha televisão. E rádio quase não tinha. Então a gente reunia a rapaziada, as moças... a gente brincava de roda, mesmo. De passar anel. E tinha umas músicas que a gente cantava envolvendo os casais. Era uma coisa assim meio que de namorico, sabe?! Aí a gente escolhia o par que a gente queria... a gente fazia a noite assim, diante do pasto verdinho. Nos domingos a gente fazia essas brincadeiras. A gente brincava de "olha o macaco na roda". A gente fazia um círculo... tudo em par, um homem e uma moça. Aí um ficava no meio e os dois círculos ao redor giravam enquanto cantavam: "Olha o macaco na roda, olha o macaco na roda". Então o macaco gritava: "Oi". Aí cada um tinha que buscar seu par. Aí o que sobrasse sem par era o macaco. Era muito divertido. Era bem diferente do que é hoje... esse povo tomando cerveja... só drogas! Lá era uma coisa tão inocente, que eu fico pensando: 'Meu Deus, como que nós brincávamos de roda!' Os rapazes e as moças. Bail

Esse tipo te recordação proporciona observações como a da Sra. Elena: "hoje a vida é tão corrida que quando a gente começa a contar alguma coisa pros filhos eles dizem: 'nossa, mãe! Era assim...?!' Uai, vocês não vêm sentar perto da gente, pra 
gente poder contar! [...] Mas é tudo muito corrido!" Elas contrastam o presente e o passado e manifestam certa surpresa diante do vivido.

Esse conjunto de atividades desenvolvidas nas comunidades paroquiais não devem ser ignorado nem lançados no esquecimento, pois são parte fundamental para se compreender a identidade local e a formação de seu povo. São elas as bases de boa parte da memória local e têm simbolicamente no prédio da igreja Matriz no centro da cidade o monumentum de tantas experiências (ARZANI, 2011). Além disso, é um campo útil a educação patrimonial por oferecer inúmeros elementos que vinculam a geração atual às memórias de tempos passados. Desse modo, pode-se considerar que o estudo das interações sociais nas comunidades religiosas desafia a comunidade acadêmica a refletir sobre esses aspectos da memória e ao mesmo tempo oferecem importantes subsídios para o trabalho pedagógico sobre a história local.

\section{Considerações finais}

Um dos méritos do projeto História Local: a Educação Patrimonial e o Exercício da Cidadania foi justamente aproximar a universidade de uma aplicação vivenciada no contexto da comunidade local. Além do exercício de técnicas e métodos da história oral, da coleta e análise de imagens, da busca por documentos, do recolhimento de materiais relevantes da culturat material e imaterial dos municípios contemplados, o projeto ainda contou com o oferecimento de oficias para desenvolvimento da "educação patrimonial" e o oferecimento de materiais de apoio produzidos no CEAPAC.

De um modo particular, conforme retratado, os estudos desenvolvidos e o contato com a população local revelaram a importância da reflexão sobre as interações sociais nos limites paroquiais. Os desafios vão desde a valorização da memória e dos aspectos cotidianos em uma análise que reduz o foco à microanálise, incidindo o destaque à contemplação de objetos à mercê do esquecimento, e às vezes desprezados pela historiografia. Desse modo, por meio do exame dos vestígios da memória de Cambira-PR é possível identificar o fluxo das interações socioparoquiais. 
São, em suma, momentos que fazem parte da trajetória da vida da comunidade Católica, mas que ao mesmo tempo talham no tempo e na memória coletiva a identidade do lugar. Para entender as atividades de integração promovidas na Paróquia, é preciso seguir o traçado do processo de formação do pequeno grupo religioso que foi tomando dimensões ao longo do tempo. Como uma instituição ativa na sociedade cambirense, a Igreja aparece como a grande responsável pelas interações vividas no cotidiano local.

Por essa perspectiva, tornam-se claras as mobilizações dos fiéis em torno do 'consenso de valor' proporcionado por essa instituição. Pessoas de diferentes esferas sociais são chamadas a compartilhar de atividades conjuntas, quer seja nas Irmandades, na preparação das festas, na Escola Paroquial, nas construções ou em outros tipos de ações. O desenvolvimento dos vínculos sociais e da voluntariedade contribuiu para a flexibilidade das relações no envolvimento com a educação religiosa (catequese) e a promoção cultural por meio do teatro e do cinema.

Assim também, manifesta-se o valor da memória das interações sociais em torno dos grupos católicos para o desenvolvimento da história e da identidade local.

\section{Referências}

Autor desconhecido. Construção da primeira Igreja de São José. 195-. Fig. 1

Autor desconhecido. Fachada da Igreja. 195-. Fig. 2

Autor desconhecido. Construção da nova Matriz da Paróquia São José. 196-. Fig. 3

Autor desconhecido. Construção da Matriz da Paróquia São José. 196-. Fig. 4

ARZANI, A. A igreja matriz como monumentum paroquial da comunidade católica cambirense. In: PELEGRINI, S. C. A.; RODRIGUES, J. P. P. (Org.). História Regional \& Patrimônio: prospecções didáticas e pedagógicas.. Maringá: CEAPAC/UEM-Editora Gráfica Massoni, 2011.

BURN, J. S. The history of parish registers in England, also of the registers of Scotland, Ireland, The East and West Indies, the dissidenters, and the Episcopal chapels in and about London. 2. ed. London: John Russell Smith, 1867.

CALSAVARA, A. Histórico: Início da cidade de Cambira. Cambira, PR: Mimeo, 1991. 
CAPELOTO, N. Cambira. Governo do Paraná, Secretaria de Estado da Cultura, 1998.

CLAUDIANO, N. Livro da memória cambirense e alguns resumos. Cambira: Nivalci Claudiano Editora, 1997.

CODEX IURIS CANONICI. Promulgado por João Paulo II em 1983. Tradução da Conferência Nacional dos Bispos do Brasil. São Paulo: Paulinas, 2002. CD-ROM.

CORRIDEN, J. A. The parish in Catholic Tradition: history, theology, and canon law. Mahwah (New Jersey): Paulist Press, 1997.

FICHTER, J. H. Dynamics of a city church. New York: Arno Press, 1978.

. Sociología. 9. ed. Barcelona: Editorial Herder, 1974.

FRENCH, K. The Good Women of the parish: gender and religion after the black death. Philadelphia: University Pensylvania Press, 2008.

. The people of the parish: community life in a late Medieval English Diocese. Philadelphia: University Pensylvania Press, 2001.

; GIBBIS, G.; KÜMIN, B. The parish in the England life, 1400-1600. Manchester: Manchester University Press, 1997.

HALBWACHS, M. La mémoire collective. Paris: PUF, 1968.

IBGE. Censo Populacional 2010. Instituto Brasileiro de Geografia e Estatística (29 de novembro de 2010). Disponível em http://www.ibge.gov.br/home/estatistica/populacao/censo2010/populacao_por_mu nicipio.shtm Acesso 11 de dezembro de 2010.

KOHLHEPP, G. Colonização agrária no Norte do Paraná. Maringá: Eduem, 2014.

LE GOFF, J. História e memória. Campinas, SP: Editora da UNICAMP, 1990.

LEVI, Gi. Sobre a micro-história. BURKE, Peter (org.). A escrita da história: novas perspectivas. 2. ed. São Paulo: Editora da Universidade Estadual Paulista, 1992.

Livro Tombo da Paróquia São José de Cambira (PR). Cambira: S/E.

Luiza Capeloto, dona de casa. Entrevista concedida em junho de 2011, em Cambira, Paraná. Tempo de duração: 15min.

MARCÍLIO, M. L. Os registros paroquiais e a história do Brasil. Revista Varia História, 31, jan. 2004, p.13-20. 
PELEGRINI, S. C. A. Apontamentos sobre uma experiência de articulação entre o ensino de história e a educação patrimonial no Paraná. Revista Cadernos do Ceom, v. 22, n. 30. 2009.

. História Local: a Educação Patrimonial e o Exercício da Cidadania, Secretaria de Estado da Ciência, Tecnologia e Ensino Superior do Paraná. Curitiba: SETI, 2008.

POLLAK, M. Memória e identidade social. Estudos Históricos, Rio de Janeiro, vol. 5, n. 10,1992 , p. 200-212.

PRINS, G. História oral. In: BURKE, P. (Org.). A escrita da história: novas perspectivas. São Paulo: Ed. da UNESP, 1992.

RUSCONI, C. (Ed.) Dicionário do grego do Novo Testamento. São Paulo: Paulus, 2003.

Selena Della Pietra, professora. Entrevista concedida em junho de 2011, em Cambira, Paraná. Tempo de duração: 32min.

Sr. José Jordão Beleze, sua esposa a Sra. Elena Nakad Beleze e o Sr. Antônio Roberto Toledo Pires. Entrevista concedida em agosto de 2010, em Cambira, Paraná. Tempo de duração: 1h12min.

THOMPSON, P. A voz do passado - história oral. Rio de Janeiro: Cortez, 1993.

WRIGLEY, E. A.; SCHOFIELD, R. The population history of England, 1541-1871: a reconstruction. Cambridge: Cambridge University Press, 2002.

Recebido em 13 de maio de 2015.

Aprovado em 24 de agosto de 2015. 